inadequately developed pathways to the pleasure centres of the brain [and] a later inability to fully experience love and pleasure". He claims the psychopath has an underactive autonomic system and the schizophrenic an overactive one: in both cases the cause is alleged to be lack of love. He does not mention the harmful effects on schizophrenics of having love too strongly expressed, as demonstrated by J. Leff and J. K. Wing. And he appears to think (in common with many neurophysiologists) that finding a correlation between a neurotransmitter and behaviour solves everything, whereas the interesting question is how its effects are mediated by the nervous system.

Walsh's book is an extraordinary potpourri of ideas drawn from many different disciplines, including sociology, neurophysiology, ethology and sociobiology. Much of it fails to inspire confidence. For example, he believes in group selection rather than selection for the individual gene; he revives Maclean's discredited theory of the triune brain; he thinks infants have to learn to walk; and he writes "altruism takes place in the limbic system" though he fails to tell us whether that system is kind to the cortex or to the cerebellum. He even manages to resuscitate that old fraud Teilhard de Chardin who saw love as a "universal psychic energy" that would reach "Point Omega" somewhere up in the "noosphere".

Moreover, many of his arguments are topsy turvy. For example, he states that maternal love is stronger than paternal despite the inconvenience and pain of pregnancy and parturition. Surely, it is, at least in part, the mother's suffering that makes her value the end product so much, for it is well established that the more a person suffers to produce something, the more he or she values it.

Among the gush and nonsense, there appears the occasional interesting finding or remark, though even these often arouse scepticism. Is it really true that from an examination of placental DNA in a variety of races one can conclude that mankind is descended from one woman who lived 200,000 years ago? Walsh is more interesting on the history of marriage than on the role of oxytocin in promoting maternal love. One is driven to the conclusion that love is not yet a suitable subject for scientific study. Indeed, Ovid knew more about "the chemistry of love" than Walsh, who confines himself to the literal meaning of that expression.

Stuart Sutherland is in the Department of Experimental Psychology, University of Sussex, Falmer, Brighton BN1 9QG, UK.

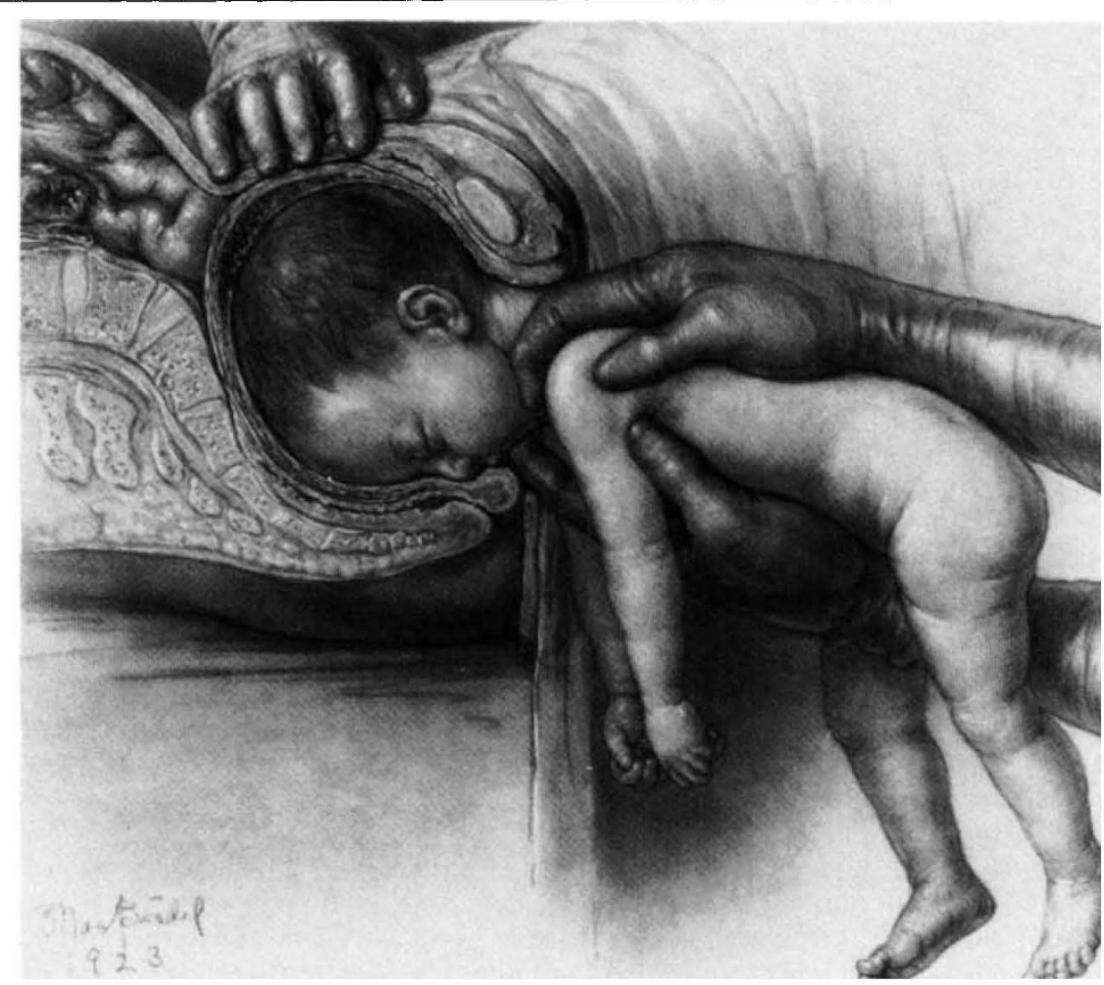

MAX Brödel (1870-1941) is widely regarded as the father of medical illustration Founding director of the pioneering academic department devoted to the subject at Johns Hopkins University, he collaborated with many distinguished physicians to provide them with teaching drawings such as the one shown here of a breech birth. Many more of these magnificent pictures are reproduced in Max Brödel: The Man Who Put Art Into Medicine, a superb biography by R. W. Crosby and J. Cody. Published by Springer, price $£ 35, \$ 49$.

\section{Good coverage}

\author{
William A. Steele
}

Dynamics of Gas-Surface Interactions.

Edited by C. T. Rettner and M. N. R. Ashfold. Royal Society of Chemistry: 1991. Pp. 366. $\$ 97.50$.

GAS-SURFACE interactions crop up in many systems, from the physical interactions of inert gases with the heterogeneous surfaces of solids with large surface areas, to the chemical interactions of gases with clean, physically perfect crystalline adsorbents. Over the past few decades, there has been a rapid advance in understanding of these systems. The authors of this book give excellent, well-written summaries of the present state of knowledge, primarily of the chemical bonding and dynamics of simple molecules at coverages of less than a monolayer on clean, wellcharacterized solid surfaces (mostly metallic).

Physical interactions and their consequences are seldom discussed other than in a chapter on energy transfer in gas-solid collisions. Most of the descriptions of chemical bonding at surfaces and of selected experimental probes of this bonding are limited to coverages sufficiently low that isolated adsorbed species are the focus of discussion. The exceptions are chapters on the chemical reactions of adsorbed species and on the kinetics of thermal desorption.

Two articles are explicitly devoted to descriptions of specific experimental techniques; namely, electron-stimulated desorption and photochemistry in the adsorbed state. The successful interpretation of desorption measurements requires a reasonably detailed model of the process, and this aspect of the problem is thoroughly discussed. There is also a chapter on theoretical progress in describing energy transfer in particlesurface collisions, as well as two chapters on the theory of dynamical chemisorption of simple gases on metal surfaces.

The problems covered in the book lie at the heart of surface chemistry, but much more theoretical insight and computing power will be required to crack them. To their credit, the authors are frank in their discussions of the difficulties as well as achievements. But if this is one of the book's strengths, then it is also a weakness, for the volume, although authoritative for the time being, is likely to become rapidly outdated.

William A. Steele is in the Department of Chemistry, 152 Davey Laboratory. The Pennsylvania State University, University Park, Pennsylvania 16802, USA. 